\title{
Delivery of Na/I Symporter Gene into Skeletal Muscle Using Nanobubbles and Ultrasound: Visualization of Gene Expression by PET
}

Yukiko Watanabe ${ }^{1}$, Sachiko Horie ${ }^{1}$, Yoshihito Funaki ${ }^{2}$, Youhei Kikuchi ${ }^{3}$, Hiromichi Yamazaki ${ }^{2}$, Keizo Ishii $^{2,3}$, Shiro Mori ${ }^{4}$, Georges Vassaux ${ }^{5,6}$, and Tetsuya Kodama ${ }^{1}$

${ }^{I}$ Graduate School of Biomedical Engineering, Tohoku University, Sendai, Japan; ${ }^{2}$ Cyclotron and Radioisotope Center, Tohoku University, Sendai, Japan; ${ }^{3}$ Graduate School of Engineering, Tohoku University, Sendai, Japan; ${ }^{4}$ Tohoku University Hospital, Sendai, Japan; ${ }^{5}$ INSERM U948, Nantes, France; and ${ }^{6}$ Institut des Maladies de l'Appareil Digestif, CHU Hôtel Dieu, Nantes, France

The development of nonviral gene delivery systems is essential in gene therapy, and the use of a minimally invasive imaging methodology can provide important clinical endpoints. In the current study, we present a new methodology for gene therapy - a delivery system using nanobubbles and ultrasound as a nonviral gene delivery method. We assessed whether the gene transfer allowed by this methodology was detectable by PET and bioluminescence imaging. Methods: Two kinds of reported vectors (luciferase and human $\mathrm{Na} / \mathrm{I}$ symporter [hNIS]) were transfected or cotransfected into the skeletal muscles of normal mice (BALB/c) using the ultrasound-nanobubbles method. The kinetics of luciferase gene expression were analyzed in vivo using bioluminescence imaging. At the peak of gene transfer, PET of hNIS expression was performed using our recently developed PET scanner, after ${ }^{124}$ I injection. The imaging data were confirmed using reverse-transcriptase polymerase chain reaction amplification, biodistribution, and a blocking study. The imaging potential of the 2 methodologies was evaluated in 2 mouse models of human pathology $(\mathrm{McH} / \mathrm{lpr}-\mathrm{RA} 1$ mice showing vascular disease and C57BL/10-mdx Jic mice showing muscular dystrophy). Results: Peak luciferase gene activity was observed in the skeletal muscle $4 \mathrm{~d}$ after transfection. On day 2 after hNIS and luciferase cotransfection, the expression of these genes was confirmed by reverse-transcriptase polymerase chain reaction on a muscle biopsy. PET of the hNIS gene, biodistribution, the blocking study, and autoradiography were performed on day 4 after transfection, and it was indicated that hNIS expression was restricted to the site of plasmid administration (skeletal muscle). Similar localized PET and ${ }^{124}$ I accumulation were successfully obtained in the diseasemodel mice. Conclusion: The hNIS gene was delivered into the skeletal muscle of healthy and disease-model mice by the ultrasound-nanobubbles method, and gene expression was successfully visualized with PET. The combination of ultrasound-nanobubble gene transfer and PET may be applied to gene therapy clinical protocols.

Received Dec. 28, 2009; revision accepted Feb. 17, 2010.

For correspondence or reprints contact: Tetsuya Kodama, Molecular Delivery System Laboratory, Department of Biomedical Engineering, Graduate School of Biomedical Engineering, Tohoku University, 2-1

Seiryo-machi, Aoba-ku, Sendai 980-8575, Japan.

E-mail: kodama@bme.tohoku.ac.jp

COPYRIGHT @ 2010 by the Society of Nuclear Medicine, Inc.
Key Words: PET; ${ }^{124}$; NIS gene; nanobubbles; ultrasound

J Nucl Med 2010; 51:951-958

DOI: 10.2967/jnumed.109.074443

G ene therapy approaches using a diverse range of preclinical models have been applied in many different clinical contexts $(1,2)$. Although viral vectors have been widely used in gene therapy, side effects such as carcinogenesis, hepatic toxicity, immunogenic, inflammation, and lower tissue specificity have been reported $(3,4)$. In this context, the development of efficient nonviral methods of gene transfer is highly desirable and is the subject of intense investigation.

The combination of nanobubbles and ultrasound has been proposed as a strategy to deliver therapeutic molecules (5), including plasmid DNA $(6,7)$. The principle is that when nanobubbles are destroyed by ultrasound, the surrounding cells are exposed to mechanical impulsive forces generated by the collapse of either the nanobubbles or the cavitation bubbles created by the collapse of the nanobubbles. These forces induce a transient membrane permeability of cells, followed by the entry of exogenous molecules into the cells (8). This mode of gene delivery has been proposed for different clinical applications including cancer gene therapy and vaccination strategies $(6,7)$.

In this context, molecular imaging could provide a minimally invasive clinical endpoint to monitor the efficacy of gene transfer. To evaluate the efficacy and anatomic site of gene delivery, this methodology requires a reporter gene and tracer molecule. Fluorescence and bioluminescence imaging methods have been widely used for the in vivo monitoring of gene expression in animal models (9). These methods are convenient; however, their clinical application remains limited because signals generated in deep tissues cannot be detected. An alternative to these methods is the use of isotopic imaging (PET or SPECT). The Na/I symporter 
(NIS) gene has been proposed as a valid reporter gene for isotopic imaging when it is associated with a relevant radiotracer. The NIS gene is an integral plasma membrane glycoprotein, endogenously expressed in the thyroid and stomach and to a lower extent in the salivary gland, breast, and thymus. The NIS protein uses the sodium gradient in cells to concentrate iodide (10). After the human NIS (hNIS) gene was cloned in 1996 (11), we and others proposed the use of NIS combined with ${ }^{99} \mathrm{~m}$ Tc or $\mathrm{Na}^{123} \mathrm{I}$ (for SPECT) (12) or $\mathrm{Na}^{124}$ I (for PET) $(13,14)$ as reporter systems to visualize and monitor gene transfer in live subjects. These imaging devices have been recently validated in humans (15).

Most current scintillator PET scanners are full width at half maximum (FWHM), providing a $1.3-\mathrm{mm}$ reconstructed image resolution at the center of the field of view and a 2-mm reconstructed image resolution within the central 5 -cm diameter in all 3 dimensions (16). This resolution is sufficient for imaging studies in rats. Recently, Ishii et al. developed a practical semiconductor animal PET scanner with a cadmium telluride detector (CdTe) (Fine Structure Imaging PET [Fine-PET]) (17). The Fine-PET scanner achieves a spatial resolution of $0.8 \mathrm{~mm}$ in FWHM within the central $20-\mathrm{mm}$ diameter of the field of view and provides a high spatial resolution of less than $1 \mathrm{~mm}$ in FWHM, which is applicable to studies in mice.

In the present study, we evaluated whether NIS gene expression mediated by ultrasound and nanobubbles could be detected by the Fine-PET scanner in mice using ${ }^{124} \mathrm{I}$ as a radiotracer.

\section{MATERIALS AND METHODS}

\section{Plasmid DNA}

Two types of plasmids were used: the luciferase reporter vector pGL3 (pGL3-control; Promega), in which the luciferase expression is driven by the Simian virus 40 (SV40) promoter, and the hNIS vector, in which the expression of the hNIS gene is driven by the cytomegalovirus promoter (18). In both cases, the promoters are strong and allow ubiquitous expression of the transgene. The plasmids were purified with an EndoFree Plasmid Mega Kit (Qiagen) and prepared at a final concentration of $1 \mathrm{mg} / \mathrm{mL}$.

\section{Nanobubbles}

Acoustic liposomes were used as nanobubbles. One milliliter of a liposome suspension (lipid concentration, $1 \mathrm{mg} / \mathrm{mL}$ ) was sonicated with a $20-\mathrm{kHz}$ device (Vibra-Cell; Sonics \& Materials Inc.) in the presence of $\mathrm{C}_{3} \mathrm{~F}_{8}$ in 7-mL sterilized vials. The bubble size distribution was determined using a laser diffraction particle size analyzer (particle range, $0.6 \mathrm{~nm}-7 \mu \mathrm{m}$ ) (ELSZ-2; Otsuka Electronics Co. Ltd.). The peak diameter expressed in terms of the size distribution and the $\zeta$-potential of the acoustic liposomes was $198 \pm 30 \mathrm{~nm}(n=3)$ and $-4.1 \pm 0.85 \mathrm{mV}(n=3)$, respectively.

\section{Ultrasound Conditions and Transfection Methods}

A $1-\mathrm{MHz}$ submersible ultrasound probe with a diameter of 30 $\mathrm{mm}$ (BFC Applications) was used in the experiments. Signal generation and pressure measurements were as previously described $(5,6)$. After the legs of the mice were shaved, the tibialis anterior (TA) muscle was immersed in water and exposed to ultrasound. The intensity was $3.0 \mathrm{~W} / \mathrm{cm}^{2}$, duty cycle was $20 \%$, number of pulses was 200 , pulse repetition frequency was 1,000 $\mathrm{Hz}$, and exposure time was $60 \mathrm{~s}$.

\section{Animal Models}

Animal studies were performed in accordance with the ethical guidelines of Tohoku University. Three types of mice were used: $40 \mathrm{BALB} / \mathrm{c}$ mice, $5 \mathrm{McH} / \mathrm{lpr}-\mathrm{RA} 1$ mice with arthritis and vasculitis disease (19), and 3 C57BL/10-mdx Jic mice with muscular dystrophy. The mice were housed in the Animal Research Institute of Tohoku University Graduate School of Medicine under specific pathogen-free conditions and had free access to food and water until the beginning of the experiments.

\section{Kinetics of Gene Expression Induced by Ultrasound and Nanobubbles}

Seven BALB/c mice (age, 6 wk; weight, 22-23 g) were used to investigate the kinetics of gene expression in the TA muscle. Two conditions were considered: pGL3 + ultrasound $(n=3)$ and pGL3 + ultrasound + nanobubbles $(n=4)$. A total volume of 30 $\mu \mathrm{L}$-comprising pGL3 $(10 \mu \mathrm{L})$, with or without nanobubbles $(15$ $\mu \mathrm{L}$ ), and saline (to reach $30 \mu \mathrm{L}$ )—was injected into the TA muscle. Mice were anesthetized with isoflurane (Forene; Abbott Scandinavia $\mathrm{AB}$ ) and subsequently injected intraperitoneally with luciferin $(150 \mathrm{mg} / \mathrm{kg}$ of body weight; Promega). After $10 \mathrm{~min}$, the mice were placed in the chamber of an in vivo real-time bioluminescence imaging system (IVIS Lumina; Xenogen) with a charge-coupled device camera (sensitivity, 400-900 nm), and the images were captured for $40 \mathrm{~s}$.

\section{Cotransfection of pGL3 and hNIS in TA Muscle}

To confirm that the hNIS gene was expressed in the TA muscle by the ultrasound-nanobubbles method, hNIS and pGL3 were cotransfected into the TA muscle. Mice that showed enhanced bioluminescence were selected as samples for a ${ }^{124} \mathrm{I}$ study. A solution containing hNIS $(10 \mu \mathrm{L})$, pGL3 $(5 \mu \mathrm{L})$, and nanobubbles $(15 \mu \mathrm{L})$ was injected into the TA muscle.

\section{RNA Isolation and Reverse-Transcriptase Polymerase Chain Reaction (RT-PCR) for Luciferase and NIS}

Nine BALB/c mice (age, $5 \mathrm{wk}$; weight, $18-20 \mathrm{~g}$ ) were used to measure luciferase and NIS gene expression in the TA muscle by RT-PCR. Three conditions were considered: saline alone $(n=3)$, pGL3 + ultrasound + nanobubbles $(n=3)$, and pGL3 + hNIS + ultrasound + nanobubbles $(n=3)$. Two days after cotransfection, the TA muscles were removed from the mice after bioluminescence was monitored. The biopsies were frozen in liquid nitrogen and homogenized (ULTRA-TURRAX T25 basic; Ika). Total RNA was extracted with an RNeasy Midi Kit (Qiagen) and an RNaseFree DNase Set (Qiagen) according to the manufacturer's protocol. Total RNA was reverse-transcribed using the RNA PCR Kit (AMV; Takara Bio Inc.) according to the manufacturer's protocol (1 $\mu \mathrm{g}$ of total RNA was used). The cDNAs were then subjected to PCR amplification using a Peltier thermal cycler (PTC-200; MJ Research). The PCR conditions were as follows: For $\beta$-actin, 3 min at $94^{\circ} \mathrm{C} ; 30$ cycles of denaturation at $95^{\circ} \mathrm{C}$ for $30 \mathrm{~s}$, annealing at $54^{\circ} \mathrm{C}$ for $30 \mathrm{~s}$, and extension at $72^{\circ} \mathrm{C}$ for $60 \mathrm{~s}$; and conclusion of the process with a 5 -min extension cycle at $72^{\circ} \mathrm{C}$. For luciferase and hNIS, $3 \mathrm{~min}$ at $94^{\circ} \mathrm{C} ; 35$ cycles of denaturation at $95^{\circ} \mathrm{C}$ for $30 \mathrm{~s}$, annealing at $53^{\circ} \mathrm{C}$ for $30 \mathrm{~s}$, and extension at $72^{\circ} \mathrm{C}$ for $60 \mathrm{~s}$; and conclusion of the process with a 5 -min extension cycle at 
$72^{\circ} \mathrm{C}$. The specific primers are shown in Table 1 . The PCR products were then separated on a $2 \%$ agarose gel.

\section{Preparation of $\mathrm{Na}^{124}$}

${ }^{124} \mathrm{I}$ was produced by the ${ }^{124} \mathrm{Te}(p, n){ }^{124} \mathrm{I}$ process-irradiation of a ${ }^{124} \mathrm{TeO}_{2}$ target with $14-\mathrm{MeV}$ protons of a $4-\mu \mathrm{A}$ beam current, depending on the target production yield of ${ }^{124} \mathrm{I}$. A dry distillation apparatus of ${ }^{124} \mathrm{I}$, which was similar to the one used in a previous study (21), was slightly modified. The radioiodine activity in the $\mathrm{NaOH}$ trap $(0.5 \mathrm{~mL} ; 0.1 \mathrm{M})$ was monitored by a NaI scintillation detector. Because of the high isotopic enrichment of the ${ }^{124} \mathrm{Te}$ oxide used for the target preparation, the calculated isotopic compositions were $98 \%$ for ${ }^{124} \mathrm{I}$ and $1 \%$ for ${ }^{123} \mathrm{I}$ at $95 \mathrm{~h}$ after the end of bombardment $(22,23)$.

\section{Biodistribution of ${ }^{124}$ |}

Fourteen BALB/c mice (age, 6 wk; weight, 18-27 g) were used to study the biodistribution of ${ }^{124} \mathrm{I}$. The TA muscle in the left leg of the mice was cotransfected with pGL3 and hNIS. The TA muscle in the right leg was injected with saline alone as a control. Four days after cotransfection, mice were injected intravenously with $370 \mathrm{kBq}$ of $\mathrm{Na}^{124}$ I dissolved in $100 \mu \mathrm{L}$ of phosphate-buffered saline ( $\mathrm{pH}$ in the physiologic range) and sacrificed after 30 (thyroid, $n=1$; other tissues, $n=4), 60(n=6)$, and 180 (thyroid, $n=3$; other tissues, $n=4$ ) minutes. The organs and tissues were quickly removed. Each sample was washed with saline solution and weighed. The radioactivity of each sample was measured by a $\gamma$-counter (AccuFLEX $\gamma 7000$; ALOKA Co. Ltd.) in the range of 400-700 keV. The radioactivity of organs and tissues was expressed as the percentage of the injected dose per gram.

\section{Blocking Study in TA Muscle}

Four BALB/c mice (age, $6 \mathrm{wk}$; weight, 21-25 g) were used for a blocking study in the TA muscle. All TA muscles were cotransfected with pGL3 and hNIS. Three days after cotransfection, the mice were divided into 2 groups. One group $(n=2)$ was injected intravenously with $100 \mu \mathrm{L}$ of $\mathrm{Na}^{124} \mathrm{I}(1.85 \mathrm{MBq})$ and sacrificed $2 \mathrm{~h}$ later. The other group $(n=2)$ was injected intraperitoneally with $100 \mu \mathrm{L}$ of $\mathrm{NaI}(57 \mathrm{mM})$. After $15 \mathrm{~min}$, $100 \mu \mathrm{L}$ of $\mathrm{Na}^{124} \mathrm{I}(1.85 \mathrm{MBq})$ were injected intravenously, and the mice were sacrificed $2 \mathrm{~h}$ later. The TA muscles were then processed for autoradiography.

\section{PET}

The Fine-PET scanner has the sensitivity of 40 counts per second $/ \mathrm{kBq} / \mathrm{mL}$. The field-of-view diameter is $64 \mathrm{~mm}$, and its axial length is $26 \mathrm{~mm}$. The energy window setting was $250 \mathrm{keV}$, open-ended (17). Six BALB/c mice (controls; age, $6 \mathrm{wk}$; weight, 22-25 g), 5 mice with arthritis and vasculitis disease (age, $16 \mathrm{wk}$; weight, 32-24 g), and 3 mice with muscular dystrophy (age, $5 \mathrm{wk}$; weight, $12-15 \mathrm{~g}$ ) were used. The TA muscle in the left leg was cotransfected with pGL3 and hNIS in the presence of ultrasound. The TA muscle in the right leg was injected with saline alone as a control. Four days after cotransfection, mice were injected intravenously with $100 \mu \mathrm{L}$ of $\mathrm{Na}^{124} \mathrm{I}$ (74 MBq). The dose concentration was chosen to be certain that informative and secure gene expression images were obtained. Then the mice were anesthetized with isoflurane $(1.0-1.5 \mathrm{~L} / \mathrm{min})$ and ventilated $(1.0$ $\mathrm{L} / \mathrm{min}$ ) through a nose cone in the bed of the scanner. A camera was used to monitor the lack of movement of the anesthetized mice and their breath to ensure that they were alive during the scanning period. The detector of the Fine-PET scanner was composed of CdTe, and the performance of the scanner was not affected by temperature. In the present study, the room temperature was kept constant $\left(20 \pm 2{ }^{\circ} \mathrm{C}\right)$ using air controllers in the PET room. Thirty minutes after injection, the PET scan was obtained, and the data were acquired for $2 \mathrm{~h}$. The Fine-PET scanner has a 3-dimensional mode, with a spatial resolution of 0.6 $\times 0.6 \times 0.6$ unit (unit $=\mathrm{mm} /$ pixel). The images were reconstructed using the Fourier rebinning-maximum-likelihood expectation maximization (FORE + ML-EM) method. In a pilot study, we have shown that integrated average pixel values in the region of interest of a mouse tumor gradually increase with increasing iteration number. However, from 30 iterations onward, these values are saturated (data not shown). Therefore, 30 iterations were chosen. PET images were obtained and visualized with image-analysis software (Image J). After PET, the mice were sacrificed, and the TA muscle was removed from the mice for autoradiography.

\section{Autoradiography}

After the mice were sacrificed, the TA muscles were quickly removed and frozen using powdered dry ice. Cryostat sections (10 $\mu \mathrm{m})$ were serially cut for each frozen sample. The sections were exposed to universal-type imaging plates. Autoradiographic images (25 $\mu \mathrm{m}$ pixels) were obtained using an imaging plate system (Bio-Imaging Analyzer BAS5000; Fuji).

\section{Statistical Analysis}

All measurements are expressed as the mean \pm SEM. Overall differences between the groups were determined by one-way ANOVA. When the one-way ANOVA results were significant for 3 samples, the differences between each group were estimated using the Tukey-Kramer test. Simple comparisons of the mean and SEM of the data were performed using the Student $t$ test. The

\section{TABLE 1. Primer Sequences}

\begin{tabular}{|c|c|c|c|c|}
\hline Primer & Sequence $\left(5^{\prime}\right.$ to $\left.3^{\prime}\right)$ & Genomic position & Product Size (bp) & Accession no. \\
\hline $\begin{array}{l}\beta \text {-actin F } \\
\beta \text {-actin R }\end{array}$ & $\begin{array}{l}\text { CGACATGGAGAAGATCTGGC } \\
\text { TCTTCATGGTGCTAGGAGCC }\end{array}$ & $\begin{array}{c}319-338 \\
1.039-1.058\end{array}$ & 739 & NM_007393 \\
\hline $\begin{array}{l}\text { Luciferase } \mathrm{F} \\
\text { Luciferase } \mathrm{R}\end{array}$ & $\begin{array}{l}\text { CCTCATAGAACTGCCTGCG } \\
\text { AGACTTCAGGCGGTCAACGAT }\end{array}$ & $\begin{array}{c}910-928 \\
1,579-1,599\end{array}$ & 689 & U47296 \\
\hline $\begin{array}{l}\text { hNIS } F^{*} \\
\text { hNIS } R^{*}\end{array}$ & $\begin{array}{l}\text { GCTGAGGACTTCTTCACCGGGGGCCG } \\
\text { GTCAGGGTTAAAGTCCATGAGGTTG }\end{array}$ & $\begin{array}{c}477-501 \\
1,034-1,058\end{array}$ & 581 & U66088 \\
\hline
\end{tabular}


FIGURE 1. Peak of gene expression in mouse TA muscle. Kinetics of luciferase gene expression in TA muscles by ultrasound-nanobubbles method. (A) Luciferase activity after transfection. (B) Bioluminescence imaging: DNA + US $(n=3)$ and DNA + US + NS $(n=4)$. Bars represent mean \pm SEM. ${ }^{\star \star} P<$ 0.01 . DNA = pGL3; US = ultrasound; $\mathrm{NB}=$ nanobubbles.

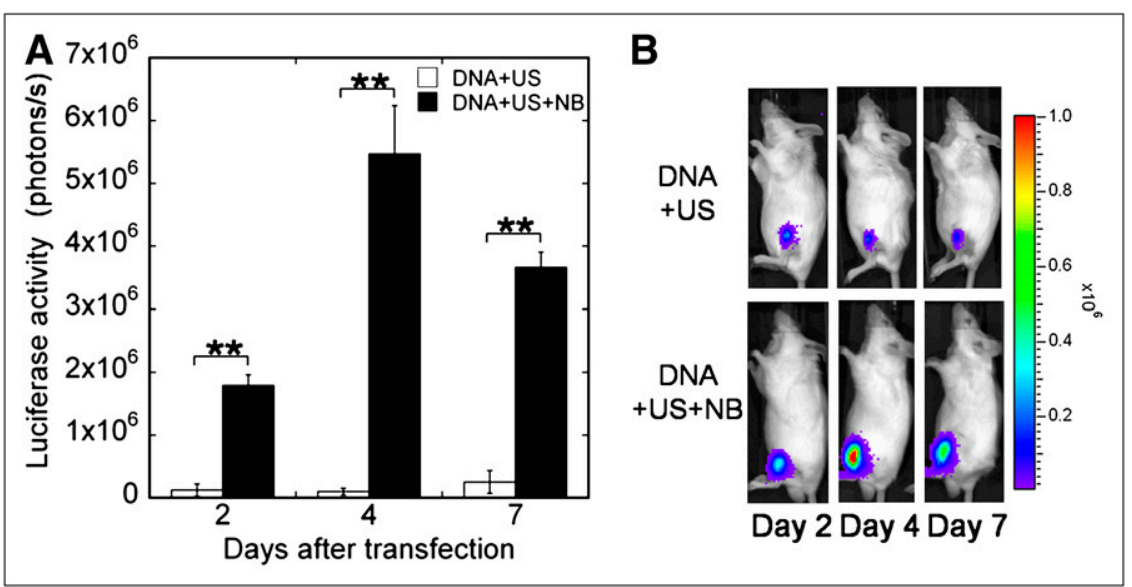

differences were considered to be significant at a $P$ value of less than 0.05 .

\section{RESULTS}

Kinetics of Gene Expression Induced by Ultrasound and Nanobubbles

To investigate the kinetics of transgene transfection in the TA muscle induced by the ultrasound-nanobubbles method, bioluminescence imaging was performed (Fig. 1). Luciferase activity was detectable when pGL3 + ultrasound were administered, but the combination of pGL3 + ultrasound + nanobubbles showed an enhanced luciferase activity on each day $(P<0.01)$. The luciferase gene expression reached a peak at $4 \mathrm{~d}$ after transfection. These results demonstrate the transient nature of ultrasound- and nanobubble-mediated gene transfer.

\section{Cotransfection with pGL3 and hNIS Genes in TA Muscle}

Transgene expression was analyzed by RT-PCR at $48 \mathrm{~h}$ after ultrasound- and nanobubble-mediated cotransfection of pGL3 and hNIS. Figure 2 demonstrates that both transgenes were coexpressed in the same TA muscle.

\section{Biodistribution of ${ }^{124}$ |}

To confirm the disposition of ${ }^{124} \mathrm{I}$ in mice and to determine whether the NIS expression detected by RT-

\begin{tabular}{|c|c|c|c|c|}
\hline & $\begin{array}{l}\text { Saline } \\
\text { alone }\end{array}$ & $+\begin{array}{l}\text { Luc } \\
+\mathrm{US}+\mathrm{NB} \\
\end{array}$ & $\begin{array}{c}\text { Luc+hNIS } \\
+\mathrm{US}+\mathrm{NB}\end{array}$ & \\
\hline $\begin{array}{l}800 \mathrm{bp}= \\
700 \mathrm{bp}= \\
600 \mathrm{bp}= \\
500 \mathrm{bp}=\end{array}$ & - & $-\infty$ & -2 & $\begin{array}{l}\text { M: DNA ladder } \\
1: \beta \text {-actin (739 bp) } \\
2: \text { Luciferase (689 bp) } \\
3: \text { hNIS (581 bp) }\end{array}$ \\
\hline & 12 & 12 & $\begin{array}{lll}1 & 2 & 3\end{array}$ & $M$ \\
\hline
\end{tabular}

FIGURE 2. RNA isolation and RT-PCR for luciferase and NIS. Gel electrophoretic analysis of RT-PCR for luciferase or hNIS expression in mouse TA muscle induced by nanobubbles and ultrasound. Lane M, 0.1- to 2-kbp ladder; lane 1, $\beta$-actin (739 bp); lane 2, luciferase (689 bp); and lane 3, hNIS (581 bp). Luc = luciferase; US = ultrasound; NB = nanobubbles.
PCR resulted in the expression of a functional protein, TA muscles of $\mathrm{BALB} / \mathrm{c}$ mice were cotransfected with pGL3 and hNIS using the ultrasound-nanobubbles method, and saline solution was injected into the right TA muscle as a control. For most organs and tissues, the accumulation of ${ }^{124} \mathrm{I}$ reached its maximum value at $60 \mathrm{~min}$ and decreased at 180 min (Fig. 3). The highest accumulation of ${ }^{124} \mathrm{I}$ was in the thyroid, and the lowest accumulation was in the brain. There was significant accumulation of ${ }^{124} \mathrm{I}$ at $60 \mathrm{~min}(P<$ $0.05)$ and $180 \mathrm{~min}(P<0.01)$ in the TA muscle transfected with hNIS, compared with the control TA muscle. These data suggest that the transfection procedure results in the synthesis of an active protein. In addition, we demonstrate here that ultrasound- and nanobubble-mediated transfection is restricted to the site of ultrasound administration, because no ectopic NIS-mediated iodide accumulation was detected.

\section{Blocking of ${ }^{124}$ I in TA Muscle}

To confirm that the ${ }^{124} \mathrm{I}$ accumulation observed in the TA muscle was indeed because of the expression of NIS, we used autoradiography to determine the accumulation of ${ }^{124} \mathrm{I}$ in the TA muscle, in the presence or absence of a large excess of cold iodide. Figure 4B shows that the accumulation of ${ }^{124} \mathrm{I}$ (Fig. 4A) was completely blocked by the injection of nonradioactive NaI (Fig. 4B).

\section{Visualization of Gene Expression}

To determine whether the NIS expression detected on biopsies (by RT-PCR [Fig. 2], biodistribution [Fig. 3], and autoradiography [Fig. 4]) could also be detected by PET, $\mathrm{BALB} / \mathrm{c}$ mice underwent ultrasound- and nanobubblemediated gene transfer on day 0 , bioluminescence imaging on day 3, and PET on day 4 (Fig. 5). The data presented in Figure 5 show a specific signal in the transfected TA muscle (left), whereas no signal was observed in the right muscle injected with saline. Autoradiographic analysis performed on muscle biopsies confirmed the PET results (Fig. 5A). These experiments, obtained with normal BALB/c mice, were repeated on mice with arthritis and vasculitis disease 


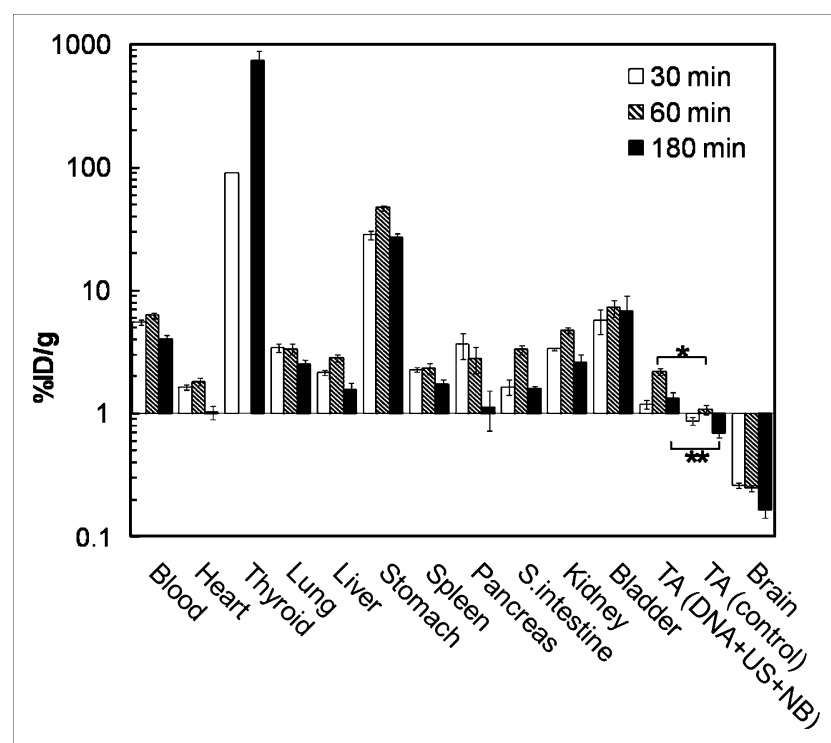

FIGURE 3. Biodistribution of ${ }^{124}$. pGL3 and hNIS were cotransfected into left TA muscle of BALB/c mice using ultrasound-nanobubbles method, and saline solution was injected into right TA muscle as control. Distribution of ${ }^{124} \mathrm{I}$ (370 kBq) is observed 30 (thyroid, $n=1$; other tissues, $n=$ 4), $60(n=6)$, and 180 (thyroid, $n=3$; other tissues, $n=4$ ) minutes after injection. Radioactivity of tissues was expressed as percentage of injected dose per gram (\%ID/g). Bars represent mean \pm SEM. ${ }^{*} P<0.05 .{ }^{* *} P<0.01$. DNA $=$ pGL3 and hNIS (cotransfection); US = ultrasound; NB = nanobubbles.

(Fig. 5B) and mice with muscular dystrophy (Fig. 5C), with similar results.

\section{DISCUSSION}

Ultrasound and nano- or microbubbles have been developed for applications in experimental therapeutics. In gene therapy, this methodology has been exploited to increase the infectivity of adeno-associated viruses (24), adenoviruses (25), and retroviruses (26). In addition, ultrasound- and nanobubble-mediated gene transfer has been used in nonviral approaches to deliver plasmid DNA to experimental tumors (27), the pancreas (28), antigenpresenting cells (29), and the kidneys (30).
Skeletal muscle is a key target for many gene therapy applications, including peripheral ischemia, secreted protein production, cancer and infection vaccines, and Duchenne muscular dystrophy (31). In this context, our results demonstrated that the ultrasound-nanobubble gene transfer technology was effective. Considering the low toxicity, ease of use, and flexibility of this methodology, ultrasound- and nanobubble-mediated gene transfer should be considered the method of choice for the TA muscle. We also demonstrated that the signal was transient and reached a peak at $4 \mathrm{~d}$ after transfection (Fig. 1). Our results are in agreement with another recent report that demonstrated that muscle was more amenable to ultrasound- and nanobubble-mediated gene transfer than were subcutaneous or orthotropic tumors (32). In addition, we demonstrated that gene transfer mediated by ultrasound and nanobubbles can also be performed on mice with arthritis or muscle degeneration, suggesting that these pathologies do not impair the transduction potential of the methodology.

We cotransfected pGL3 and hNIS into the TA muscle using the ultrasound-nanobubbles method (Figs. 2-5). This cotransfection method is based on the hypothesis that 2 plasmids have the same backbone and promoter. The promoter of pGL3 is the SV40, and the promoter of the hNIS gene is the cytomegalovirus. It has been reported that the gene expression levels differed (SV40 < cytomegalovirus) when plasmids with the SV40 and cytomegalovirus promoters both expressed the same gene product (33). So et al. showed a correlation between the ${ }^{125}$ I uptake of the hNIS gene and the bioluminescence activity induced by the luciferase gene when a plasmid with both the luciferase and hNIS gene was transfected in vitro (34). Therefore, it is reasonable to select mice and to visualize the gene expression of hNIS using PET based on the expression of the luciferase gene. In addition, Figure 2 clearly showed that both genes were expressed after cotransfection in the TA muscle. Extrapolated to a physiopathologic situation and on the basis of these data, it is possible to foresee therapeutic strategies combining the action of at least 2 transgenes carried by different expression plasmids. This flexibility may provide the means for a mix-and-match approach to provide optimal therapeutic efficiency.

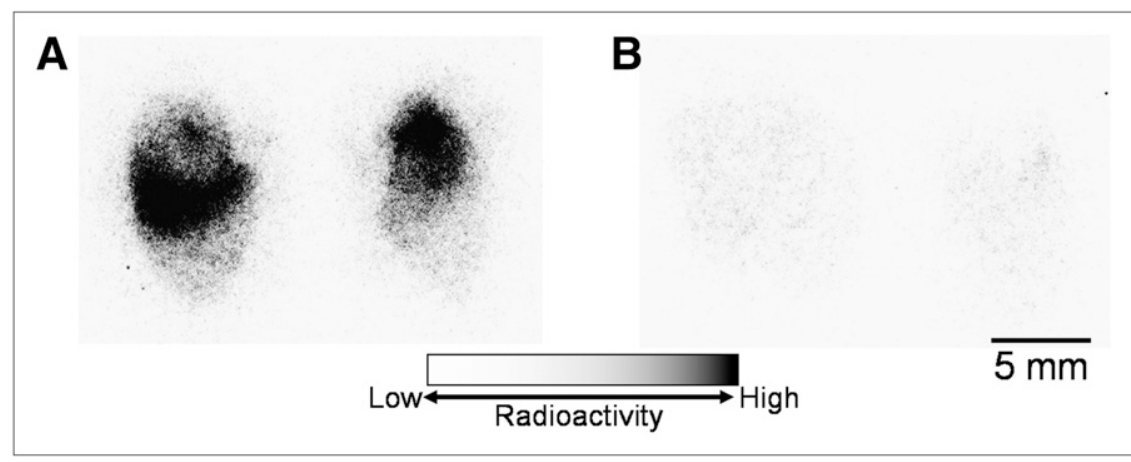

FIGURE 4. Blocking of ${ }^{124}$ In TA muscle. Autoradiography localization of ${ }^{124}$ | in mouse TA muscle axial slices. Mice cotransfected with pGL3 and hNIS were divided into 2 groups $4 \mathrm{~d}$ after transfection. (A) One group was intravenously injected with $\mathrm{Na}^{124}$ (1.85 MBq) and sacrificed $2 \mathrm{~h}$ later. (B) Other group was intraperitoneally injected with $\mathrm{Nal}$. After $15 \mathrm{~min}, \mathrm{Na}^{124}$ (1.85 $\left.\mathrm{MBq}\right)$ was intravenously injected, and group was sacrificed $2 \mathrm{~h}$ later. Color bar shows logarithmic radioactivity. 


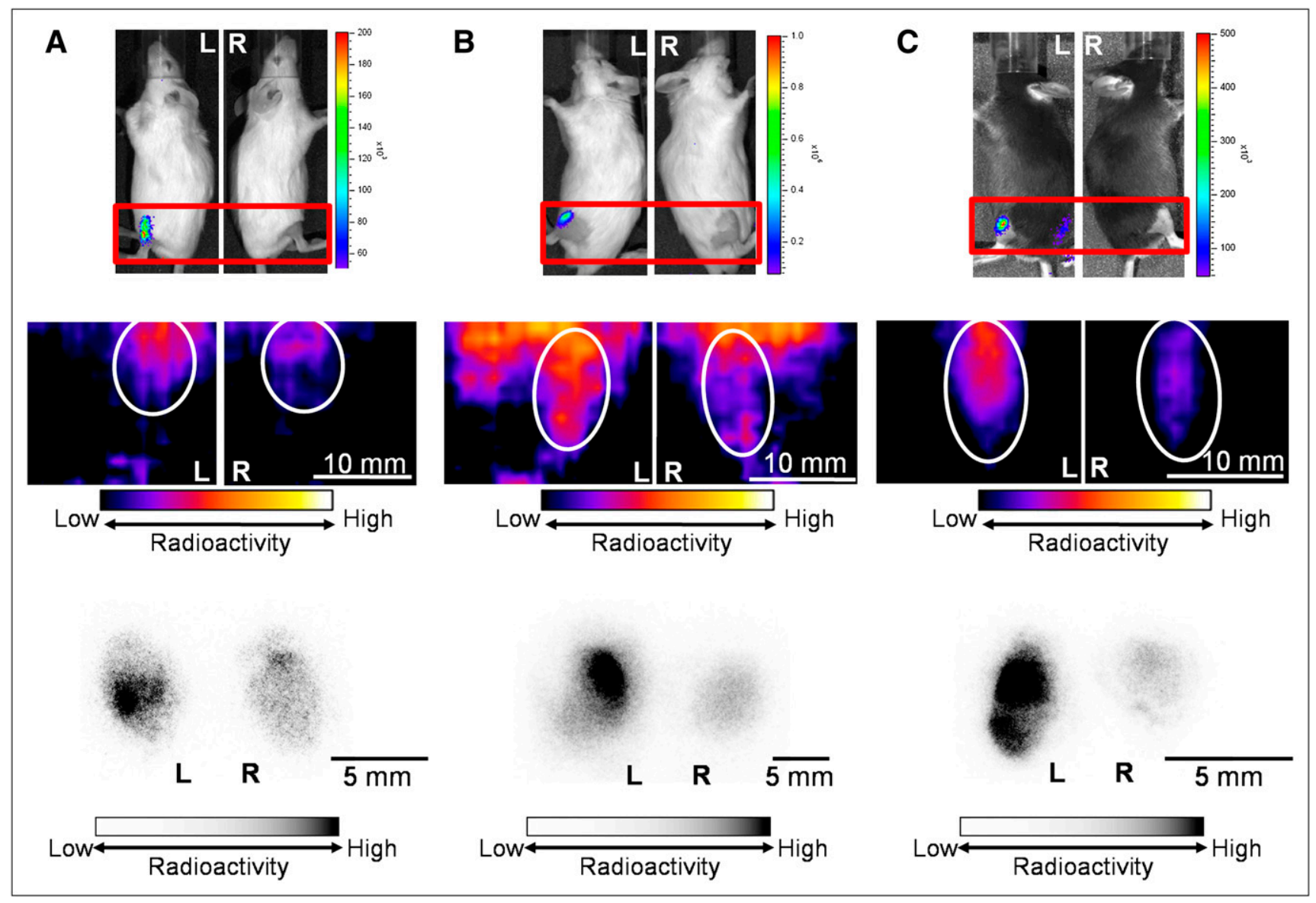

FIGURE 5. Visualization of gene expression. We used 3 types of mice: control (A), arthritis and vasculitis disease model (B), and muscular dystrophy model (C). In all images, left TA muscle was cotransfected with pGL3 and hNIS by ultrasoundnanobubbles method, and right TA muscle was injected with saline. In all images, upper row shows bioluminescence image $3 \mathrm{~d}$ after transfection, middle row shows PET images $4 \mathrm{~d}$ after transfection ( $\mathrm{Na}^{124}$ [ [74 MBq] intravenously), and bottom row shows autoradiograph of TA sections. Radioactive tracer accumulated in left TA section, whereas it did not accumulate in right TA section. Color bar shows logarithmic radioactivity.

The biodistribution study was important to confirm the radiation exposure before PET. Figure 3 demonstrates that specific accumulation of ${ }^{124} \mathrm{I}$ was observed in the thyroid and stomach when endogenous NIS was expressed (35) and in the bladder as a result of iodide excretion (36). Low levels of ${ }^{124} \mathrm{I}$ accumulation were observed in the brain, indicating that iodide does not pass the blood-brain barrier (37). In addition, we demonstrated that ultrasound- and nanobubble-mediated transfection is restricted to the site of ultrasound administration, because no ectopic NIS-mediated iodide accumulation was detected in sites not subjected to the transfection procedure. These results are in agreement with a previous ${ }^{125} \mathrm{I}$ study that suggested ${ }^{124} \mathrm{I}$ and ${ }^{125} \mathrm{I}$ are appropriate radiotracers to study accumulation (38). In addition, the radioiodide activity of the TA muscle transfected with the hNIS gene, compared with the control TA muscle, indicated a 2 -fold accumulation. This result demonstrates that the specific accumulation of ${ }^{124} \mathrm{I}$ in the TA muscle occurred by the ectopic expression of the hNIS gene. Because accumulation of ${ }^{124} \mathrm{I}$ in the blood was observed until $180 \mathrm{~min}$, the residual ${ }^{124} \mathrm{I}$ internal exposure should be investigated in a future study.

To confirm the specific binding of ${ }^{124} \mathrm{I}$ in mouse TA muscle, we injected nonradioactive $\mathrm{NaI}$ before the administration of ${ }^{124} \mathrm{I}$ (Fig. 4). The uptake of ${ }^{124} \mathrm{I}$ was blocked by NaI, indicating that hNIS was actually transfected in the TA muscle. The results of the biodistribution and blocking studies showed that the hNIS gene was transfected in the TA muscle by the ultrasound-nanobubbles method, and the accumulation of ${ }^{124} \mathrm{I}$ was because of the expression of the hNIS gene.

In this study, we verified the effectiveness of gene delivery using the ultrasound-nanobubbles method and the visualization of gene expression using PET to develop gene therapy. The expression of the hNIS gene was confirmed at the peak of gene transfer, determined by bioluminescence imaging. However, longitudinal studies are required for this expression to be applicable as a clinical endpoint. We administered ${ }^{124} \mathrm{I}$ (74 MBq intravenously) for PET (Fig. 5). This dose is 10 times larger than that used in 
previous studies (39) and is similar to that used in a clinical study (40). Acute radiation injury in mice will occur at this dose, and longitudinal studies are not possible under these conditions. We administered this dose for the following reasons: this was the first study, to our knowledge, using ${ }^{124} \mathrm{I}$ and the Fine-PET scanner, and the sensitivity of the Fine-PET scanner is 40 counts per second $/ \mathrm{kBq} / \mathrm{mL}$ (17) (one tenth that of the commercially available small-animal PET system). In future studies, we will conduct a longitudinal analysis of gene expression with a lower injected dose of ${ }^{124} \mathrm{I}$.

\section{CONCLUSION}

This study demonstrates for the first time, to our knowledge, the proof of principle that PET can be used to visualize ultrasound- and nanobubble-mediated gene transfer. This technology provides a new platform to detect nonviral-mediated gene transfer and, extrapolated to patients, a new clinical endpoint for future clinical trials that may include patients with genetic disorders (i.e., vascular diseases and muscular dystrophy). In this perspective, we are developing a new plasmid that combines a therapeutic gene and the hNIS gene to visualize the therapeutic effect; we are also improving the ultrasound-nanobubble hNISPET system to improve the levels of transfection and expression.

\section{ACKNOWLEDGMENTS}

This study was supported in part by the following: grants-in-aid for JSPS Fellows 21-7073 and 21-7271; a grant-in-aid for scientific research for a JSPS Postdoctoral Fellowship for Foreign Researchers P09127; grants-in-aid for scientific research (B) (19390507) and (B) (20300173); a grant-in-aid for exploratory research (21650124); a grantin-aid for scientific research on a priority area, MEXT (17012002, 18014002, and 20015005); a grant for research on advanced medical technology, Ministry of Health, Labor, and Welfare of Japan (H19-nano-010); a grant for research for promoting technological seeds (03-017); and a grant from the Japan-France Integrated Action Program (SAKURA) Joint Project.

\section{REFERENCES}

1. Edelstein ML, Abedi MR, Wixon J, Edelstein RM. Gene therapy clinical trials worldwide 1989-2004: an overview. J Gene Med. 2004;6:597-602.

2. Penuelas I, Mazzolini G, Boan JF, et al. Positron emission tomography imaging of adenoviral-mediated transgene expression in liver cancer patients. Gastroenterology. 2005;128:1787-1795.

3. Bekeredjian R, Chen S, Frenkel PA, Grayburn PA, Shohet RV. Ultrasoundtargeted microbubble destruction can repeatedly direct highly specific plasmid expression to the heart. Circulation. 2003;108:1022-1026.

4. Inubushi M, Tamaki N. Radionuclide reporter gene imaging for cardiac gene therapy. Eur J Nucl Med Mol Imaging. 2007;34(suppl 1):S27-S33.

5. Watanabe Y, Aoi A, Horie S, et al. Low-intensity ultrasound and microbubbles enhance the antitumor effect of cisplatin. Cancer Sci. 2008;99:2525-2531.

6. Aoi A, Watanabe Y, Mori S, Takahashi M, Vassaux G, Kodama T. Herpes simplex virus thymidine kinase-mediated suicide gene therapy using nano/ microbubbles and ultrasound. Ultrasound Med Biol. 2008;34:425-434.
7. Chen R, Chiba M, Mori S, Fukumoto M, Kodama T. Periodontal gene transfer by ultrasound and nano/microbubbles. J Dent Res. 2009;88:1008-1013.

8. Kodama T, Tomita Y, Watanabe Y, Koshiyama K, Yano T, Fujikawa S. Cavitation bubbles mediated molecular delivery during sonoporation. J Biomech Sci Eng. 2009;4:124-140.

9. Weissleder R, Pittet MJ. Imaging in the era of molecular oncology. Nature. 2008; 452:580-589.

10. Chen RF, Li ZH, Pan QH, et al. In vivo radioiodide imaging and treatment of pancreatic cancer xenografts after MUC1 promoter-driven expression of the human sodium-iodide symporter. Pancreatology. 2007;7:505-513.

11. Dai G, Levy O, Carrasco N. Cloning and characterization of the thyroid iodide transporter. Nature. 1996;379:458-460.

12. Yeom CJ, Chung JK, Kang JH, et al. Visualization of hypoxia-inducible factor-1 transcriptional activation in C6 glioma using luciferase and sodium iodide symporter genes. J Nucl Med. 2008;49:1489-1497.

13. Groot-Wassink T, Aboagye EO, Wang Y, Lemoine NR, Reader AJ, Vassaux G. Quantitative imaging of $\mathrm{Na} / \mathrm{I}$ symporter transgene expression using positron emission tomography in the living animal. Mol Ther. 2004;9:436-442.

14. Fortin MA, Salnikov AV, Nestor M, Heldin NE, Rubin K, Lundqvist H. ImmunoPET of undifferentiated thyroid carcinoma with radioiodine-labelled antibody cMAb U36: application to antibody tumour uptake studies. Eur J Nucl Med Mol Imaging. 2007;34:1376-1387.

15. Barton KN, Stricker H, Brown SL, et al. Phase I study of noninvasive imaging of adenovirus-mediated gene expression in the human prostate. Mol Ther. 2008;16: 1761-1769.

16. Tai YC, Ruangma A, Rowland D, et al. Performance evaluation of the microPET focus: a third-generation microPET scanner dedicated to animal imaging. $\mathrm{J} \mathrm{Nucl}$ Med. 2005;46:455-463.

17. Ishii K, Kikuchi Y, Matsuyama S, et al. First achievement of less than $1 \mathrm{~mm}$ FWHM resolution in practical semiconductor animal PET scanner. Nucl Instrum Meth Phys Res A. 2007;576:435-440.

18. Chisholm EJ, Vassaux G, Martin-Duque P, et al. Cancer-specific transgene expression mediated by systemic injection of nanoparticles. Cancer Res. 2009; 69:2655-2662.

19. Mori S, Tanda N, Ito MR, et al. Novel recombinant congenic mouse strain developing arthritis with enthesopathy. Pathol Int. 2008;58:407-414.

20. Huang M, Batra RK, Kogai T, et al. Ectopic expression of the thyroperoxidase gene augments radioiodide uptake and retention mediated by the sodium iodide symporter in non-small cell lung cancer. Cancer Gene Ther. 2001;8:612-618.

21. Glaser M, Mackay DB, Ranicar ASO, Waters SL, Brady F, Luthra SK. Improved targetry and production of iodine-124 for PET studies. Radiochim Acta. 2004;92: 951-956.

22. Yamazaki H, Ishii K, Funaki Y, et al. Production of "no carrier added" iodine124 from a reusable enriched tellurium-124 dioxide target and its application to an ultra-high resolution animal PET study. Paper presented at: Proceedings of 16th Pacific Basin Nuclear Conference; October 13-18, 2008; Aomori, Japan.

23. Kanai Y, Yamazaki H, Funaki Y, et al. Radiosynthesis of $\left[{ }^{124} \mathrm{I}\right]$ iomazenil and imaging of rat brain by means of semiconductor high resolution animal PET scanner [abstract]. J. Nucl. Med. 2008;49:308P.

24. Li HL, Zheng XZ, Wang HP, Li F, Wu Y, Du LF. Ultrasound-targeted microbubble destruction enhances AAV-mediated gene transfection in human RPE cells in vitro and rat retina in vivo. Gene Ther. 2009;16:1146-1153.

25. Howard CM, Forsberg F, Minimo C, Liu JB, Merton DA, Claudio PP. Ultrasound guided site specific gene delivery system using adenoviral vectors and commercial ultrasound contrast agents. J Cell Physiol. 2006;209:413-421.

26. Taylor SL, Rahim AA, Bush NL, Bamber JC, Porter CD. Targeted retroviral gene delivery using ultrasound. J Gene Med. 2007;9:77-87.

27. Hayashi S, Mizuno M, Yoshida J, Nakao A. Effect of sonoporation on cationic liposome-mediated IFN $\beta$ gene therapy for metastatic hepatic tumors of murine colon cancer. Cancer Gene Ther. 2009;16:638-643.

28. Chai R, Chen S, Ding J, Grayburn PA. Efficient, glucose responsive and isletspecific transgene expression by a modified rat insulin promoter. Gene Ther. 2009;16:1202-1209.

29. Un K, Kawakami S, Suzuki R, Maruyama K, Yamashita F, Hashida M. Enhanced transfection efficiency into macrophages and dendritic cells by the combination method using mannosylated lipoplexes and bubble liposomes with ultrasound exposure. Hum Gene Ther. 2010;21:65-74.

30. Xing Y, Pua EC, Lu X, Zhong P. Low-amplitude ultrasound enhances hydrodynamic-based gene delivery to rat kidney. Biochem Biophys Res Commun. 2009;386:217-222.

31. Braun S. Muscular gene transfer using nonviral vectors. Curr Gene Ther. 2008;8: 391-405.

32. Tsai KC, Liao ZK, Yang SJ, et al. Differences in gene expression between sonoporation in tumor and in muscle. J Gene Med. 2009;11:933-940. 
33. Yang JP, Huang L. Direct gene transfer to mouse melanoma by intratumor injection of free DNA. Gene Ther 1996;3:542-548.

34. So MK, Kang JH, Chung JK, et al. In vivo imaging of retinoic acid receptor activity using a sodium/iodide symporter and luciferase dual imaging reporter gene. Mol Imaging. 2004;3:163-171.

35. Spitzweg C, Joba W, Eisenmenger W, Heufelder AE. Analysis of human sodium iodide symporter gene expression in extrathyroidal tissues and cloning of its complementary deoxyribonucleic acids from salivary gland, mammary gland, and gastric mucosa. J Clin Endocrinol Metab. 1998;83: 1746-1751.

36. Dwyer RM, Bergert ER, O'Connor MK, Gendler SJ, Morris JC. Sodium iodide symporter-mediated radioiodide imaging and therapy of ovarian tumor xenografts in mice. Gene Ther. 2006;13:60-66.
37. Hwang do W, Kang JH, Chang YS, et al. Development of a dual membrane protein reporter system using sodium iodide symporter and mutant dopamine D2 receptor transgenes. J Nucl Med. 2007;48:588-595.

38. Groot-Wassink T, Aboagye EO, Glaser M, Lemoine NR, Vassaux G. Adenovirus biodistribution and noninvasive imaging of gene expression in vivo by positron emission tomography using human sodium/iodide symporter as reporter gene. Hum Gene Ther. 2002;13:1723-1735.

39. Pandey SK, Sajjad M, Chen Y, et al. Comparative positron-emission tomography (PET) imaging and phototherapeutic potential of ${ }^{124}$ I-labeled methyl-3-(1'iodobenzyloxyethyl)pyropheophorbide-a vs the corresponding glucose and galactose conjugates. J Med Chem. 2009;52:445-455.

40. Phan HT, Jager PL, Paans AM, et al. The diagnostic value of ${ }^{124} \mathrm{I}-\mathrm{PET}$ in patients with differentiated thyroid cancer. Eur J Nucl Med Mol Imaging. 2008;35:958-965. 